\title{
Prenatal radiation exposure
}

\author{
Mustafa Gök, ${ }^{1}$ Murat Bozkurt, ${ }^{2}$ Serkan Guneyli, ${ }^{3}$ Duygu Kara Bozkurt, ${ }^{1}$ Mehmet \\ Korkmaz, ${ }^{4}$ Nuri Peker ${ }^{5}$
}

Keywords: Ionizing radiation, nonionizing radiation, prenatal exposure, CT, fetal anomaly

\begin{abstract}
Pregnant women may be exposed to nonionizing, ionizing radiation and contrast media via diagnostic or therapeutic procedures and workplace exposure. When computed tomography or magnetic resonance imaging is performed on a pregnant woman, the effects of exposure to radiation, high magnetic fields and contrast media, which can be risky for a fetus, should be considered. Nonionizing radiation that is not significantly risky for a fetus includes microwave, ultrasound, radio frequency and electromagnetic waves, while ionizing radiation that can be teratogenic, carcinogenic or mutagenic includes particles and electromagnetic radiation. The effects of radiation are associated with the level of exposure and stage of fetal development. Organogenesis (two to seven weeks after conception) and the early fetal period (eight to fifteen weeks after conception) are the most sensitive stages for a fetus. Noncancerous health effects have not been determined at any stage of gestation with less than $50 \mathrm{mGy}(5 \mathrm{rad})$ exposure dose of ionizing radiation. Higher exposure levels may lead to spontaneous
\end{abstract}

abortion, growth restriction, and mental retardation. The risk of cancer is increased regardless of the dose. Although the use of iodinated contrast media is generally thought to be safe during pregnancy, the risk of fetal hypothyroidism should be considered and it should be used only when necessary. The use of gadolinium-based contrast media during pregnancy is controversial because of the lack of clinical data. The purpose of this article is to review the existing literature regarding the prenatal radiation exposure and to discuss fetal risk of radiation.

${ }^{1}$ Department of Radiology, Kafkas University School of Medicine, Kars, Turkey

${ }^{2}$ Department of Obstetrics and Gynecology, Kafkas University School of Medicine, Kars, Turkey

${ }^{3}$ Department of Radiology, Bülent Ecevit University of Medicine, Zonguldak, Turkey

${ }^{4}$ Department of Radiology, Dumlupinar University of Medicine, Kutahya, Turkey

${ }^{5}$ Department of Obstetrics and Gynecology, Acıbadem University Atakent Hospital, Turkey

Please cite this paper as: Gök M, Bozkurt M, Guneyli S, Kara Bozkurt D, Korkmaz M, Peker N. Prenatal Radiation Exposure. Proceedings in Obstetrics and Gynecology, 2015;5(1):Article 2 [10 p.]. Available from: http://ir.uiowa.edu/pog/Free full text article.

Corresponding author: Murat Bozkurt, Assistant Professor, Kafkas Üniversity Kampüsü Sağlık Araștırma ve Uygulama Hastanesi. Bülbül Mahallesi. Kombine Yolu Üzeri 3600 Kars/TURKEY. Tel: 905322279072, 905056330044. Fax: 047422514 30. E-Mail: jindrmb@yahoo.com

Financial Disclosure: The authors report no conflict of interest.

Received: 26 November 2014; received in revised form:15 June 2015; accepted POG in Press, 15 June 2015

Copyright: (c) 2015 Gok et al. This is an open-access article distributed under the terms of the Creative Commons Attribution License, which permits unrestricted use, distribution, and reproduction in any medium, provided the original author and source are credited. 


\section{Introduction}

All persons are regularly exposed to radiation such as environmental radiation and radiation from industrial and medical sources. In the past 10 years, radiological examinations performed in pregnant women have increased by $107 \%$ and the greatest increase is seen in use of contrast enhanced computed tomography (CT) ${ }^{1}$ Although ultrasonography (US) is the first preferred radiological examination in pregnant women, $\mathrm{CT}$ and magnetic resonance imaging (MRI) are occasionally required in some cases, and these examinations often require the intravenous injection of contrast media. Physicians should know about the potential effects of radiation and contrast media so as to provide appropriate management of pregnant women. ${ }^{2}$ The aim of this study is to review the literature regarding prenatal radiation exposure and to discuss the types, effects and fetal risks of radiation.

\section{Forms of radiation}

Radiation, emitted as particles or waves is a kind of fast-moving energy which is classified as nonionizing and ionizing radiation. In nonionizing low-frequency radiation, energy is dispersed through heat and increased molecular movement; this includes visible light, ultraviolet rays, microwave, ultrasound, radio frequency and some electromagnetic waves. lonizing radiation includes particles (alpha and beta particles) and electro-magnetic radiation (gamma rays and $\mathrm{x}$-rays) and it can alter the normal structure of a living cell. $^{3}$ The average annual exposure of radiation from cosmic rays, radioactive substances in the environment and naturally occurring radiation in the human body is $1 \mathrm{mGy}(0.1 \mathrm{rad}){ }^{4}$ Common medical applications of nonionizing and ionizing radiation are presented in Table 1.

Table 1. Common medical applications of non-ionizing and ionizing radiation

\begin{tabular}{|c|l|}
\hline \multicolumn{1}{|c|}{ Type of radiation } & \multicolumn{1}{c|}{ Medical application } \\
\hline Ionizing radiation & \\
\hline Gamma Rays & PET \\
\hline & RT \\
\hline X-rays & SPECT \\
\hline & CT \\
\hline & DSA \\
\hline & Duel-energy x-ray absorptiometry \\
\hline & Fluoroscopy \\
\hline & Mammography \\
\hline Non-ionizing radiation & RT \\
\hline Electromagnetic and RF waves & Radiography \\
\hline Ultrasound & MRI \\
\hline & US \\
\hline
\end{tabular}

Abbreviations: CT, computed tomography; DSA, digital substraction angiography; MRI, magnetic resonance imaging; PET, positron emission tomography; RT, radiation therapy; RF, radiofrequency; SPECT, single-photon emission computed tomography; US, ultrasonography. 


\section{Non-ionizing radiation}

Nonionizing radiation interacts with the tissue through the formation of heat. The effect of in utero exposure to nonionizing radiation has been evaluated, and no major risks have been detected. ${ }^{5}$

The most common type of diagnostic nonionizing radiation performed in pregnant women is ultrasound. Previous studies reported that there is no relationship between prenatal US and adverse fetal effects such as childhood malignancies including mental retardation. ${ }^{6}$ However, US has thermal tissue effects and it is advised to be performed using the lowest possible exposure setting under the ALARA (as low as reasonably achievable) principle. $^{7}$

MRI is another type of nonionizing radiation used in medicine. ${ }^{2}$ The advantages of MRI are multiplanar capability and excellent evaluation of soft-tissue. ${ }^{8}$ The risks of MRI in pregnant women have been evaluated with computer simulations and animal models. The risk to the fetus on 1.5Tesla (The unit for the MRI systems that shows the strength of the magnetic field they produce. 1 Tesla $=10,000$ gauss, earth's magnetic field is 0.5 gauss) MRI appear to be nonsignificant. ${ }^{9}$ However, the possible risks of MRI with higher field strength have not been extensively evaluated. In 2007, the American College of Radiology (ACR) guidelines for MRI recommended that MRI should be used when the risk-benefit ratio warrants the study. The heat of the magnetic field may cause a possible risk to the fetus, especially in the first trimester. ${ }^{10}$ Another potential risk of MRI is that of acoustic injury. However, previous studies reported that this possible risk seems less likely, since sound is attenuated through amniotic fluid and it generally affects the fetus at a level of less than $30 \mathrm{~dB} \cdot{ }^{10}$ In 1991, the Safety Committee of the Society of MRI stated that MRI may be performed in pregnant women when US is inadequate or insufficient. They also stated that pregnant women should be informed about the fact that MRI during pregnancy did not have any deleterious effects to date. ${ }^{11,12}$

\section{lonizing Radiation}

lonizing radiation acts directly with the biochemical structures in tissue (including proteins, DNA, and other molecules) or indirectly by leading to the formation of free radicals. The effects of exposure may be classified under 2 types; deterministic and stochastic effects. ${ }^{13}$

\section{$\underline{\text { Deterministic effects }}$}

Deterministic effects are caused by high exposure doses of radiation. These effects are predictable and involve multicellular injury, including chromosome aberrations. ${ }^{14}$ The threshold dose for the evaluation of the pregnancy has been estimated to be 150 mGy (15 rad). ${ }^{15}$ At this dose, it is recommended that the pregnancy should be evaluated for the need of intervention, such as termination of pregnancy. Theoretical risks at this dose include a less than 3\% chance of cancer development, a $6 \%$ chance of mental retardation, loss of intelligence quotient (IQ) points by 30 points per $100 \mathrm{mGy}$, 
and a $15 \%$ chance of microcephaly. ${ }^{13,14}$ However, the risks depend on the timing and dose of the exposure in early gestation (Table 2) ${ }^{16}$ Although there is theoretical risk with any exposure to ionizing radiation, the dose exposed to the fetus from a single diagnostic examination is generally much less than 50 mGy (5 rad) which can be regarded as threshold value for noncancerous health effects of ionizing radiation. Table 3 presents the average values for fetal radiation doses of diagnostic imaging examinations. ${ }^{2,8,17,18}$

Table 2. Potential effects to the fetus of various radiation exposure doses in various gestational ages ${ }^{16}$

\begin{tabular}{clll}
\hline Gestational age (week) & \multicolumn{3}{l}{ Potential effects of radiation exposure doses } \\
\hline & & & \\
& $<50 \mathrm{mGy}$ & $50-100 \mathrm{mGy}$ & $>100 \mathrm{mGy}$ \\
$0-2$ & None & None & None \\
$3-4$ & None & Probably none & Possible spontaneous abortion \\
$5-10$ & None & Uncertain & Possible malformations \\
$11-17$ & None & Uncertain & Possible deficits in IQ or mental retardation \\
$18-27$ & None & None & IQ deficits not detectable at diagnostic doses \\
$>27$ & None & None & None applicable to diagnostic medicine \\
\hline
\end{tabular}

Abbreviations: IQ, intelligence quotient.

\section{Stochastic effects}

Stochastic effects are the result of cellular damage, presumably at the DNA level, that leads to cancer or other germ cell mutations. Stochastic effects have no threshold value and are thought to occur with any exposure dose of ionizing radiation. The severity of stochastic effects is independent of the radiation dose. The radiation dose estimated for stochastic effects was established at $50 \mathrm{mGy}(5 \mathrm{rad}) .{ }^{10}$ It is considered that this level provides a margin of safety from higher exposures. ${ }^{14,19}$ It is reported that the risk of childhood cancer doubles with exposures over $50 \mathrm{mGy}{ }^{20}$ However, this value is not regarded as current in these days, since no radiation effects have been clearly reported at this level. In 2008, ACR provided guidelines for imaging in pregnant women and estimated fetal risk of various radiation exposure doses in various gestational ages [Table 2]. ${ }^{16}$ These values are provided from animal studies, epidemiological studies of survivors in Japan at the time of atomic bombings and studies of groups exposed to radiation for medical reasons such as radiation therapy for uterus carcinoma. ${ }^{9}$

\section{Contrast media}

Studies of iodinated low osmolality contrast media (LOCM) in diagnostic Xray and $\mathrm{CT}$, and gadolinium-based contrast agents (GBCAs) in MRI in pregnancy have been limited, and their effects on the human embryo or fetus are imperfectly understood. The assumption is that all iodinated and gadolinium-based contrast media 
behave similarly crossing the bloodplacenta barrier into the fetus. ${ }^{21}$ The agents will be excreted through the urine into the amniotic fluid which will then be swallowed by the fetus. ${ }^{23}$ It is then possible that a small amount will be absorbed from the gut of the fetus with the additional swallowed gadoliniumbased contrast agents eliminated back into the amniotic fluid. There are no data available to assess the rate of clearance of contrast media from the amniotic fluid. $^{21}$

\section{Table 3. Fetal radiation doses of common imaging examinations $\mathbf{s}^{2,8,17,18}$}

\begin{tabular}{|c|c|}
\hline Type of examination & Fetal dose* (mGy) \\
\hline \multicolumn{2}{|l|}{ Very low dose examinations ( $<0.1 \mathrm{mGy})$} \\
\hline Cervical spine radiography (2 views) & $<0.001$ \\
\hline Radiography of any extremity & $<0.001$ \\
\hline Mammography (2 views) & $0.001-0.01$ \\
\hline Chest radiography (2 views) & $0.0005-0.01$ \\
\hline \multicolumn{2}{|l|}{$\begin{array}{l}\text { Low to moderate dose examinations }(0.1-10 \\
\text { mGy) }\end{array}$} \\
\hline \multicolumn{2}{|l|}{ Radiography } \\
\hline Abdominal radiography & $0.1-3.0$ \\
\hline Lumber spine radiography & $1.0-10$ \\
\hline IVP & $5-10$ \\
\hline Double contrast barium enema & $1.0-2.0$ \\
\hline \multicolumn{2}{|l|}{ 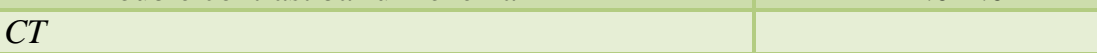 } \\
\hline Head or neck CT & $1.0-10$ \\
\hline Chest CT or CT pulmonary angiography & $0.01-0.66$ \\
\hline Limited CT pelvimetry & $<1$ \\
\hline \multicolumn{2}{|l|}{ Nuclear Medicine } \\
\hline Low dose perfusion scintigraphy & $0.1-0.5$ \\
\hline Technetium-99m bone scintigraphy & $4-5$ \\
\hline Pulmonary digital substraction angiography & 0.5 \\
\hline \multicolumn{2}{|l|}{ Higher dose examinations (10-50 mGy) } \\
\hline Abdominal CT & $1.3-35$ \\
\hline Pelvic CT & $10-50$ \\
\hline 18 F PET/CT whole-body scintigraphy & $10-50$ \\
\hline
\end{tabular}

Abbreviations: CT, computed tomography; 18 F PET/CT, 2-[fluorine-18]fluoro-2-deoxy-D-glucose positron emission tomography/computed tomography; IVP, intravenous pyelography.

Annual average background radiation=1.1-2.5 $\mathrm{mGy}$.

*Fetal exposure varies with gestational age, maternal body habitus, and exact acquisition parameters.

\section{lodinated Low Osmolality Contrast} Media (LOCM)

In-vivo tests in animals have shown no evidence of either mutagenic or teratogenic effects with $\mathrm{LOCM}^{8,9}$ No adequate and well-controlled teratogenic studies of the effects of these media in pregnant women have been performed. The effects of LOCMs on fetal thyroid functions are crucial 
because the fetal thyroid plays an important role in the development of the central nervous system. ${ }^{9}$ There have been rare reports of hypothyroidism developing in the newborn infant after the administration of iodinated contrast medium during pregnancy; however, this occurred only following amino fetography using fat-soluble iodinated contrast medium which was performed in the past to detect congenital malformations. Intravenous (IV) administration of iodinated contrast media doesn't affect short-term neonatal thyroid stimulating hormone (TSH), likely because the overall amount of excess iodide in the fetal circulation is very small; however, the long term effects are unknown. ${ }^{21}$ To date, there has been no documented case of neonatal hypothyroidism from the maternal intravascular injection of watersoluble iodinated contrast agents. ${ }^{23}$ There have been no other adverse effects that have been reported in the fetus or neonate following administration of LOCM; however, information on this issue is inadequate. ${ }^{21}$

Gadolinium-based contrast agents $\underline{\text { (GBCAs) }}$

To date, there have been no known adverse effects to the human fetus reported when clinically recommended dosages of GBCAs have been given to pregnant women. A single cohort study of 26 women exposed to gadolinium chelates during the first trimester pf pregnancy showed no evidence of teratogenesis or mutagenesis in their progeny. ${ }^{24}$ However, no adequate and well-controlled teratogenic studies of the effects of these media in pregnant women have been performed. GBCAs nephrogenic systemic fibrosis (NSF) is a potential risk, but there are no known cases of NSF linked to the use of GBCAs in pregnant patients to date. Gadolinium chelates may accumulate in the amniotic fluid; therefore, there is the potential for dissociation of the toxic free gadolinium ion, conferring a potential risk for the development of NSF in the child or mother. Because the risk is unknown, it is generally recommended that gadolinium chelates not be used routinely in pregnant patients. ${ }^{21}$ Since it is unclear how GBCAs will affect the fetus, they should be used only with caution, when their usage is considered critical and the potential benefits justify the potential risk to the unborn fetus. If a GBCA is to be used in a pregnant patient, one of the agents believed to be at low risk for the development of $\mathrm{NSF}^{25}$ should be used at the lowest possible dose to achieve diagnostic results. In pregnant patients with severely impaired renal function, the same precautions should be used as in non-pregnant patients.

General Recommendation of the Committee on Drugs and Contrast Media

At the present time, the Committee on Drugs and Contrast Media recommends the following in patients in whom imaging studies are requested that may require the use of iodinated contrast media or gadolinium based contrast media. $^{21}$

A) The radiologist should confer with the referring physician and document the following in the radiology report or the patient's medical record:

1. That information requested from the CT or MRI study cannot be 
acquired without the use of IV contrast or by using other imaging methods.

2. The information needed affects the care of the patient and/or fetus during the pregnancy.

3. That the referring physician is of the opinion that it is not prudent to wait to obtain this information until after the patient is no longer pregnant.

B) It is recommended that both pregnant patients undergoing $\mathrm{CT}$ or MRI with contrast media and their referring physicians should indicate that they understand the potential risks and benefits of procedures to be performed, alternative diagnostic options available (if any), and that they wish to proceed.

\section{Management of patients exposed to radiation during pregnancy}

Although avoidance of exposure to ionizing radiation is preferable for pregnant women, exposure may occur in some situations such as medical necessity, unknown pregnancy at the time of diagnostic or therapeutic intervention and workplace exposure. When there is an exposure, the first step is to estimate the cumulative radiation dose to the fetus. Approximate fetal radiation doses for common radiological procedures are given in Table 3., 2,8,17,18 Complex calculations are required for internal radiation doses because substances needed for fetal growth and development such as iodine may concentrate in fetal tissue and radioactive substances may concentrate in maternal tissues surrounding the uterus. Once the fetal radiation dose is estimated, the potential health effects can be evaluated. Discussions with pregnant women should include the immediate and short-term risks to the fetus, as well as the estimated long-term risks to the fetus such as cancer. Thereafter, pregnant women should be counseled in a nondirective manner and encouraged to make an informed decision about pregnancy management. $^{26}$

All pregnant women are entitled to counseling before exposure to radiation. The extent of communication about the effects of radiation should be related to the level of risk. A detailed explanation should be provided if the anticipated fetal dose or actual exposure exceeds 10 mGy (1 rad). ${ }^{4}$ Women should be counseled that diagnostic radiography during pregnancy is safe under most circumstances and radiation exposure from a single diagnostic imaging procedure has not been associated with an increase in fetal anomalies or pregnancy loss. ${ }^{17}$ Exposure to a cumulative dose of less than 50 mGy that is approximately equivalent to the radiation dose of 500 chest radiographies or 100 abdominal CT scans has not been shown to affect pregnancy outcomes compared with control populations exposed to background radiation. ${ }^{3,4}$

\section{Conclusion}

Pregnant women are at risk of being exposed to radiation caused by medical and environmental reasons. Nonionizing radiation and contrast media used in some radiological examinations are considered less risky than ionizing radiation; however, further studies are required to clearly evaluate the effects 
of nonionizing radiation and contrast media. Ionizing radiation has significant risks for the fetus including teratogenic, carcinogenic and mutagenic effects. Physicians should be especially aware of the risks of medical imaging modalities performed in pregnant women, ionizing radiation is more deleterious in the first trimester of pregnancy compared to other trimesters and its effects are associated with the level of exposure doses. Unlike carcinogenic effects which are independent of the dose, other effects of ionizing radiation have not been identified at any stage of gestation with less than 50 mGy (5 rad) exposure dose. Although a diagnostic radiography or single imaging procedure during pregnancy is generally not associated with an increase in fetal anomalies or pregnancy loss, physicians should be careful about medical imaging procedures. The use of imaging procedures such as US and MRI should be encouraged instead of imaging procedures with ionizing radiation.

\section{References}

1. Lazarus E, Debenedectis C, North D, Spencer PK, Mayo-Smith WW. Utilization of imaging in pregnant patients: 10-year review of 5270 examinations in 3285 patients--19972006. Radiology. 2009 May;251(2):51724. doi: 10.1148/radiol.2512080736. Epub 2009 Mar 17. PubMed PMID: 19293204.

2. Williams PM, Fletcher S. Health effects of prenatal radiation exposure. Am Fam Physician. 2010 Sep 1;82(5):488-93. PubMed PMID: 20822083.
3. Ratnapalan S, Bentur Y, Koren G. "Doctor, will that $\mathrm{X}$-ray harm my unborn child?". CMAJ. 2008 Dec 2;179(12):1293-6. doi: 10.1503/cmaj.080247. Erratum in: CMAJ. 2009 Apr 28;180(9):952. Dosage error in article text. http://dx.doi.org/10.1503/cmaj.080247

PubMed PMID: 19047611.

4. International Commission on Radiological Protection. Pregnancy and medical radiation. Ann ICRP. 2000;30(1):iii-viii, 1-43. PubMed PMID: 11108925.

5. Feychting M. Non-cancer EMF effects related to children. Bioelectromagnetics. 2005;Suppl 7:S69-74. PubMed PMID: 16142774.

6. Stålberg $\mathrm{K}$, Haglund $\mathrm{B}$, Axelsson $\mathrm{O}$, Cnattingius $\mathrm{S}$, Pfeifer $\mathrm{S}$, Kieler $\mathrm{H}$. Prenatal ultrasound and the risk of childhood brain tumour and its subtypes. $\mathrm{Br} J$ Cancer. 2008 Apr 8;98(7):1285-7. doi: 10.1038/sj.bjc.6604284. Epub 2008 Mar 18. PubMed PMID: 18349848.

7. American College of Obstetricians and Gynecologists. ACOG Practice Bulletin No. 101: Ultrasonography in pregnancy. Obstet Gynecol. 2009 Feb;113(2 Pt 1):451-61 10.1097/AOG.0b013e31819930b0.

PubMed PMID: 19155920.

8. Chen MM, Coakley FV, Kaimal A, Laros RK Jr. Guidelines for computed tomography and magnetic resonance imaging use during pregnancy and lactation. Obstet Gynecol. 2008 Aug;112(2 Pt 1):333-40. doi: 10.1097/AOG.0b013e318180a505.

PubMed PMID: 18669732.

9. Patel SJ, Reede DL, Katz DS, Subramaniam R, Amorosa JK. Imaging the pregnant patient for nonobstetric conditions: algorithms and radiation dose considerations. Radiographics. 2007 Nov-Dec;27(6):1705-22. DOI: http://dx.doi.org/10.1148/rg.276075002. PubMed PMID: 18025513. 
10. Coakley FV, Glenn OA, Qayyum A, Barkovich AJ, Goldstein R, Filly RA. Fetal MRI: a developing technique for the developing patient. AJR Am J Roentgenol. 2004 Jan;182(1):243-52. PubMed PMID: 14684546.

11. Shellock FG, Crues JV. MR procedures: biologic effects, safety, and patient care. Radiology. 2004 Sep;232(3):635-52. Epub 2004 Jul $29 . \quad$ DOI: http://dx.doi.org/10.1148/radiol.2323030 830 PubMed PMID: 15284433.

12. MRIsafety.com [Web site.] http://www.mrisafety.com

13. Wieseler KM, Bhargava $P$, Kanal KM, Vaidya S, Stewart BK, Dighe MK. Imaging in pregnant patients: examination appropriateness. Radiographics. 2010 Sep;30(5):121529; discussion 1230-3. doi: 10.1148/rg.305105034. PubMed PMID: 20833847.

14. Bushberg JT, Seibert JA, Leidholdt EM, Boone JM. The essential physics of medical imaging. 2nd ed. Philadelphia, Pa: Lippincott Williams \& Wilkins; 2002.

15. Martin JN Jr, Ridgway LE 3rd, Connors JJ, Sessums JK, Martin RW, Morrison JC. Angiographic arterial embolization and computed tomography-directed drainage for the management of hemorrhage and infection with abdominal pregnancy. Obstet Gynecol. 1990 Nov;76(5 Pt 2):941-5. http://dx.doi.org/10.1097/00006250199011000-00053 PubMed PMID: 2216261.

16. American College of Radiology. ACR practice guidelines for imaging pregnant or potentially pregnant adolescent and women with ionizing radiation. Reston, VA: American College of Radiology, 2008. Available from: http://www.who.int/tb/advisory bodies/i mpact measurement taskforce/meeting s/prevalence survey/imaging pregnant arc.pdf
17. ACOG Committee on Obstetric Practice. ACOG Committee Opinion. Number 299, September 2004 (replaces No. 158, September 1995). Guidelines for diagnostic imaging during pregnancy. Obstet Gynecol. 2004 Sep;104(3):64751. PubMed PMID: 15339791.

18. Wall BF, Meara JR, Muirhead CR, Bury RF, Murray M. Protection of pregnant patients during diagnostic medical exposures to ionising radiation: advice from the Health Protection Agency, the Royal College of Radiologists and the College of Radiographers. Documents of the Health Protection Agency: Radiation, Chemical and Environmental Hazards. United Kingdom, 2009. Available from: http://www.who.int/tb/advisory bodies/i mpact measurement taskforce/meeting s/prevalence survey/imaging regnant hpa.pdf

19. Wagner LK, Lester RG, Saldana LR. Exposure of the Pregnant Patient to Diagnostic Radiations: A Guide to Medical Management, 2nd ed. Madison, WI: Medical Physics Publishing; 1997.

20. Brent RL. Saving lives and changing family histories: appropriate counseling of pregnant women and men and women of reproductive age, concerning the risk of diagnostic radiation exposures during and before pregnancy. Am J Obstet Gynecol. 2009 Jan;200(1):4-24. doi: 10.1016/j.ajog.2008.06.032. PubMed PMID: 19121655.

21. American College of Radiology (ACR) Manual on Contrast Media, Version 9. ACR Committee on Drugs and Contrast Media, 2013. Available from: http://www.acr.org/quality\%20safety/resources/ /media/37D8442 8BF1D4E1B9A3A2918DA9E27A3.pdf/

22. Panigel $M$, Wolf $G$, Zeleznick $A$. Magnetic resonance imaging of the placenta in rhesus monkeys, Macaca mulatta. J Med Primatol. 1988;17(1):318. PubMed PMID: 3367357. 
23. Bourjeily G, Chalhoub M, Phornphutkul C, Alleyne TC, Woodfield CA, Chen KK.Neonatal thyroid function: effect of a single exposure to iodinated contrast medium in utero. Radiology. 2010 Sep;256(3):744-50. doi: 10.1148/radiol.10100163. Epub 2010 Jul 15. PubMed PMID: 20634430.

24. De Santis M, Straface G, Cavaliere AF, Carducci B, Caruso A. Gadolinium periconceptional exposure: pregnancy and neonatal outcome. Acta Obstet Gynecol Scand. 2007;86(1):99-101. DOI: $\quad 10.1080 / 00016340600804639$. PubMed PMID: 17230297.

25. Thomsen HS, Morcos SK, Almén $T$, Bellin MF, Bertolotto M, Bongartz G, Clement $O$, Leander $P$, Heinz-Peer $G$, Reimer $P$, Stacul $F$, van der Molen $A$, Webb JA; ESUR Contrast Medium Safety Committee. Nephrogenic systemic fibrosis and gadolinium-based contrast media: updated ESUR Contrast Medium Safety Committee guidelines. Eur Radiol. 2013 Feb;23(2):307-18. doi: 10.1007/s00330-012-2597-9. Epub 2012 Aug 4. PubMed PMID: 22865271.

26. Ratnapalan S, Bona N, Chandra K, Koren G. Physicians' perceptions of teratogenic risk associated with radiography and $\mathrm{CT}$ during early pregnancy. AJR Am J Roentgenol. 2004 May;182(5):1107-9.

http://dx.doi.org/10.2214/ajr.182.5.1821 107 PubMed PMID: 15100102. 